\title{
Screening of Lettuce Germplasm for Agronomic Traits under Low Water Conditions
}

\author{
Renée L. Eriksen and Caleb Knepper \\ U.S. Department of Agriculture-Agricultural Research Service, 1636 East \\ Alisal Street, Salinas, CA 93905 \\ Michael D. Cahn \\ University of California Cooperative Extension, 1432 Abbott Street, Salinas, \\ CA 93901
}

\section{Beiquan Mou' \\ U.S. Department of Agriculture-Agricultural Research Service, 1636 East Alisal Street, Salinas, CA 93905}

Additional index words. Lactuca sativa, Lactuca serriola, breeding, drought, abiotic stress tolerance

Abstract. After a preliminary screening of over 3500 cultivars, we selected 200 butterhead, cos, crisphead, leaf, and stem lettuce (Lactuca sativa L.) and wild prickly lettuce (Lactuca serriola L.) varieties to test under high water (150\% evapotranspiration [ET]) and low water $(50 \%$ ET) conditions in the field, and tracked commercially relevant traits related to growth and marketability, maturity, and physiology. Plants typically reduced growth and appeared to reallocate developmental resources to achieve maturity quickly, as indicated by traits such as increased core length. This strategy may allow them to complete their life cycle before severe drought stress proves lethal. Although most cultivars experienced a reduction in growth under low water conditions relative to high water conditions, some cultivars had a significantly reduced yield penalty under stress conditions. Among the different types of lettuce, the fresh weight (FW) of cos cultivars was most affected by drought stress, and the FW of leaf lettuce was least affected. Cos cultivars tended to bolt early. Crisphead cultivars Cal-West 80, Heatmaster, and Marion produced large heads and did not bolt under low water treatments, and butterhead cultivars Buttercrunch and Bibb also produced relatively large heads with very little bolting and no signs of tipburn. The four green leaf cultivars Slobolt, Grand Rapids, Western Green, and Australian showed no statistically significant difference in FW among high and low water treatments in multiple trials, and may be good choices for growers who wish to minimize losses under reduced irrigation. The identification of potentially drought-tolerant varieties and the information from this study may be helpful for cultivar selection by growers under drought conditions, but this study also serves as a step forward in the genetic improvement of lettuce to drought stress.

Lettuce (L. sativa) is the second largest vegetable crop produced in the United States with 261,000 acres of head, leaf, and cos

\footnotetext{
Received for publication 12 Jan. 2016. Accepted for publication 1 Apr. 2016.

This project was supported by the Specialty Crop Block Grant Program at the U.S. Department of Agriculture (USDA) through grant 14-SCBGP-CA-0006. The technical assistance of Elisabeth Wood, Chenping $\mathrm{Xu}$, Dave Milligan, Sharon Benzen, Javier Mora, David Lara, Mark Trent (USDA-ARS), Laura Murphy, and Barry Farrara (UC Cooperative Extension) is greatly appreciated. Manuscript review by James $\mathrm{McCreight}$ and Chenping $\mathrm{Xu}$ is greatly appreciated. Its contents are solely the responsibility of the authors and do not necessarily represent the official views of the USDA. Mention of trade names or commercial products in this publication is solely for the purpose of providing specific information and does not imply recommendation or endorsement by the U.S. Department of Agriculture.

USDA is an equal opportunity provider and employer. ${ }^{1}$ Corresponding author. E-mail: beiquan.mou@ars. usda.gov.
}

(romaine) lettuce harvested in 2014. Slightly more than $75 \%$ of the lettuce grown in the United States in 2014 was grown in California with a value to growers of over $\$ 2$ billion (USDA NASS, 2015). Water use in lettuce varies with planting time, proximity to the coast, and irrigation method. Irrigation requirements range from 1 to 2.5 acre-feet of water per acre in the Central Coast region to 3.5 acre-feet per acre in southern desert regions (Cahn, 2009). These water requirements are becoming more difficult for growers to meet during droughts and when water supplies are limited. Indeed, lettuce production in the Central Valley of California has largely ceased due to the cost of irrigation water. As a leafy green crop consisting of $95 \%$ to $97 \%$ water that depends on high soil water potential to maintain cell turgor for palatability, lettuce production could continue to face costly yield losses as water supplies continue to diminish. Improving lettuce tolerance to low water conditions is thus becoming a priority.

Previous research on drought tolerance and drought resistance in lettuce is limited, and has largely centered on root qualities. Jackson (1995) reported differences in root architecture in cultivated $L$. sativa cv. Salinas and its wild progenitor (Kesseli et al., 1991) Lactuca serriola. Cultivated L. sativa tends to produce more lateral roots, greater total root length, and more external links near the soil surface than $L$. serriola, whereas deeper in the soil profile, L. serriola produces more lateral roots and greater root length than $L$. sativa (Jackson, 1995). Jackson suggested that more root mass near the surface of the soil in cultivated $L$. sativa was the result of inadvertent selection by breeders while applying water and fertilizers to the soil surface. Gallardo et al. (1996) compared leaf water potential, net photosynthesis, stomatal conductance, and biomass in shallow-rooted cultivated crisphead lettuce and $L$. serriola, and found that drying in the upper layer of soil had no effect on the deep-rooted $L$. serriola but caused a reduction in leaf water potential and photosynthesis in shallowrooted $L$. sativa. This suggested that the shallow-rooted L. sativa is at a disadvantage when the surface soil is dry. However, Kerbiriou et al. (2013) looked at two butterhead cultivars, Matilda and Pronto, and found that generally early and late drought tended to increase root growth during the recovery period. Their work suggests that even shallow-rooted cultivated $L$. sativa plants exposed to drought are able to prepare for future drought conditions by increasing root growth to capture water held at depth in the soil.

Other evidence that root traits contribute significantly to drought tolerance in lettuce comes from studies of quantitative trait loci (QTL) for drought tolerance. Johnson et al. (2000) identified 13 QTLs in mapping populations of a $L$. sativa $\times L$. serriola hybrid under mild drought stress, and found that the QTLs for taproot length and deep soil water extraction colocalized within the genome. Uwimana et al. (2012) did a similar study in search of stress-response QTLs, and found that QTLs for vigor colocalized with some root growth QTLs identified by Johnson et al. (2000), and they reported that the positive effect of vigor for these QTLs came from the deep-rooted $L$. serriola parent. Wei et al. (2014) found agreement between the QTLs of Johnson et al. (2000) for root water acquisition and their own QTLs for salt tolerance. Hartman et al. (2014) also looked for drought-response QTL in the same mapping population, but found little correlation among QTLs. In part, the goal of these studies has been to identify regions for markerassisted selection, and progress has been made in the production of a high-density genetic map (Atkinson et al., 2013; Truco et al., 2007) and the publishing of the L. sativa genome (Truco et al., 2013).

Our study takes a different approach to understanding drought tolerance in lettuce; it is targeted as an approach that will yield immediate small benefits to water-strapped growers as well as greater, long-term benefits in conjunction with QTL studies and markerassisted selection. In preliminary studies, over 
3500 varieties of lettuce maintained in the germplasm repository at the USDA Agricultural Research Services (ARS) location in Salinas, CA, were screened for droughttolerant traits such as delayed wilting, FW under drought conditions, and relative water content (RWC) using the methods described in the work of Knepper and Mou (2015). From these preliminary greenhouse trials, 200 cultivars were selected and grown under carefully controlled field trial conditions to further examine the response of various growth, maturity, and physiological traits under high and low water treatments.

In screening for drought-tolerant cultivars, two approaches can be taken: 1) identify the cultivars that produce the most biomass with the least number of unfavorable traits under low water conditions regardless of the traits they display under high water conditions; 2) identify the cultivars that grow similarly under both high and low water conditions. We placed the most importance on traits that affect marketable yield such as FW in this study, but head height and width, as well as firmness of crisphead varieties have historically been important for marketability and are thus also reported. Our goals were 3-fold: 1) to identify cultivars that produce high biomass under low water conditions; 2) to identify cultivars that perform similarly under high and low water conditions; and 3) to describe differences among cultivars in drought tolerance that can be used by breeders to develop varieties of lettuce that perform well under drought.

\section{Materials and Methods}

Trials 1 and 2 (24 May to 2 Aug. 2013; 1 Aug. to 25 Oct. 2013), Salinas, CA. In the field under two different irrigation treatments (high and low water conditions), 200 cultivars of butterhead, cos (romaine), crisphead, green leaf, red leaf, stem (Lactuca sativa), and wild prickly lettuce (L. serriola) were evaluated for various traits. Seeds were obtained from germplasm collections maintained by the USDA ARS in Salinas, CA, and cultivars were selected based on preliminary greenhouse screenings (Knepper and Mou, 2015). Some substitutions of cultivars were made in trial 2 due to availability of seed.

All trials followed a randomized complete block, split-split-plot design, where main plots were water treatment $(150 \%$ and $50 \%$ ET for high and low water conditions, respectively), and subplots were divided by cultivar type (i.e., crisphead, butterhead). Plots were further split by cultivar, and each plot consisted of a single bed, $1 \mathrm{~m}$ in width and $9.1 \mathrm{~m}$ in length. Borders of 1-2 rows of lettuce buffered each whole plot. Each plot was replicated four times.

Sprinkler irrigation was used to establish the stand, and the amount of irrigation applied to each treatment was uniform to this point. After stand establishment $\approx 4$ weeks after planting, irrigation was switched to a drip system using a custom-built manifold, which allowed for two precisely controlled water treatments within the same field. Plants were then exposed to high and low water treatments, and irrigation was based on estimates of crop ET calculated using the online irrigation-scheduling tool CropManage (ucanr.edu/cropmanage) (Cahn et al., 2013). The amount of water recommended for treatments by CropManage was based on reference ET rates from a weather station on site operated by the California Irrigation Management Information System, as well as daily estimates of crop ET coefficients $\left(K_{\mathrm{c}}\right)$, and information on the soil type and irrigation system. High water treatments were maintained at $150 \%$ of the field ET CropManage so that ET rates were consistently above $100 \%$. Low water treatments were maintained at $\approx 50 \%$ of the field ET (Fig. 1).

Flow meters were installed to record the amount of water applied in the high and low water treatments. Tensiometers (The Irrometer Company, Inc., Riverside, CA) and Watermark $^{\circledR}$ soil moisture meters (The Irrometer Company, Inc.) were installed to monitor soil moisture conditions. Tensiometers measured the soil water tension, that is, the approximate pressure required by roots to pull water from the soil (irrometer.com); these were installed at depths of 20 and $46 \mathrm{~cm}$ ( 8 and 18 inches) in each main plot receiving high and low water treatments. Watermark ${ }^{\circledR}$ sensors also measure soil water tension, but can measure a wider range of tensions than tensiometers, and these were placed at depths of 20 and $46 \mathrm{~cm}$ ( 8 and 18 inches) in each main plot. Watermark sensors and tensiometers were read $5 \mathrm{~d}$ per week during the experimental portion of the trial.

An all-purpose nitrogen, phosphorus, and potassium fertilizer $(6 \mathrm{~N}-20 \mathrm{P}-20 \mathrm{~K})$ was applied at listing at $338.5 \mathrm{~kg} \cdot \mathrm{ha}^{-1}$ for both trials, and an acid spray $(6 \mathrm{~N}-16 \mathrm{P}-0 \mathrm{~K}-1.94 \mathrm{~S})$ was applied before planting to prevent soil crusting. Between 3 and 4 weeks after planting, a granular sidedressing of ammonium sulfate $(21 \mathrm{~N}-0 \mathrm{P}-0 \mathrm{~K}-24 \mathrm{~S})$ at $336.3 \mathrm{~kg} \cdot \mathrm{ha}^{-1}$ was applied, and $\approx 2-3$ weeks later following thinning, a second ammonium sulfate treatment was applied.

Trial 3 (8 July to 19 Sept. 2014), Salinas, $C A$. Fifty cultivars from butterhead, cos, crisphead, green leaf, and red leaf lettuce types with the least number of significant differences in traits between high and low water treatments in trials 1 and 2 were selected for trial 3. Seed availability was also a factor in choosing cultivars for trial 3 . The same experimental design and irrigation conditions were applied in trial 3 as in trials 1 and 2 .

The field used for trial 3 was fertilized and heavily irrigated 2 months before planting on July 8, 2014, following the start of a trial that was ultimately cancelled due to poor germination. In May 2014, an all-purpose fertilizer $(6 \mathrm{~N}-20 \mathrm{P}-20 \mathrm{~K})$ was applied at listing of the beds at $336.3 \mathrm{~kg} \cdot \mathrm{ha}^{-1}$ followed by an acid spray $(7 \mathrm{~N}-7 \mathrm{P}-0 \mathrm{~K}-7.46 \mathrm{~S})$ and heavy irrigation. Before planting in July for the trial reported here, fertilizer $(6 \mathrm{~N}-20 \mathrm{P}-20 \mathrm{~K})$ was applied again at listing at $358.7 \mathrm{~kg} \cdot \mathrm{ha}^{-1}$, followed by the acid spray $(7 \mathrm{~N}-7 \mathrm{P}-0 \mathrm{~K}-7.46 \mathrm{~S})$ to prevent soil crusting. Ammonium sulfate $(21 \mathrm{~N}-0 \mathrm{P}-0 \mathrm{~K}-24 \mathrm{~S})$ fertilizer at $336.3 \mathrm{~kg} \cdot \mathrm{ha}^{-1}$ was applied 4 weeks after planting, and the ammonium sulfate treatment was applied again 2 weeks later after thinning.

Traits scored. Traits were scored by cultivar type at harvest maturity. Four individual plants were chosen at random from each cultivar in each plot for data collection. Green and red leaf lettuce varieties were harvested $\approx 8$ weeks after planting, followed by butterhead varieties. Crisphead cultivars were harvested $\approx 10$ weeks after planting, after which followed the harvest of cos varieties. The presence or absence of a bolt was scored in the field at time of harvest. FW was measured after removing the first layer of outer leaves, and height and width was recorded for butterhead, crisphead, and cos cultivars only as head size is linked to marketability in these lettuce types. Following harvest, heads were sliced in half, and the length of the core was recorded to the longest

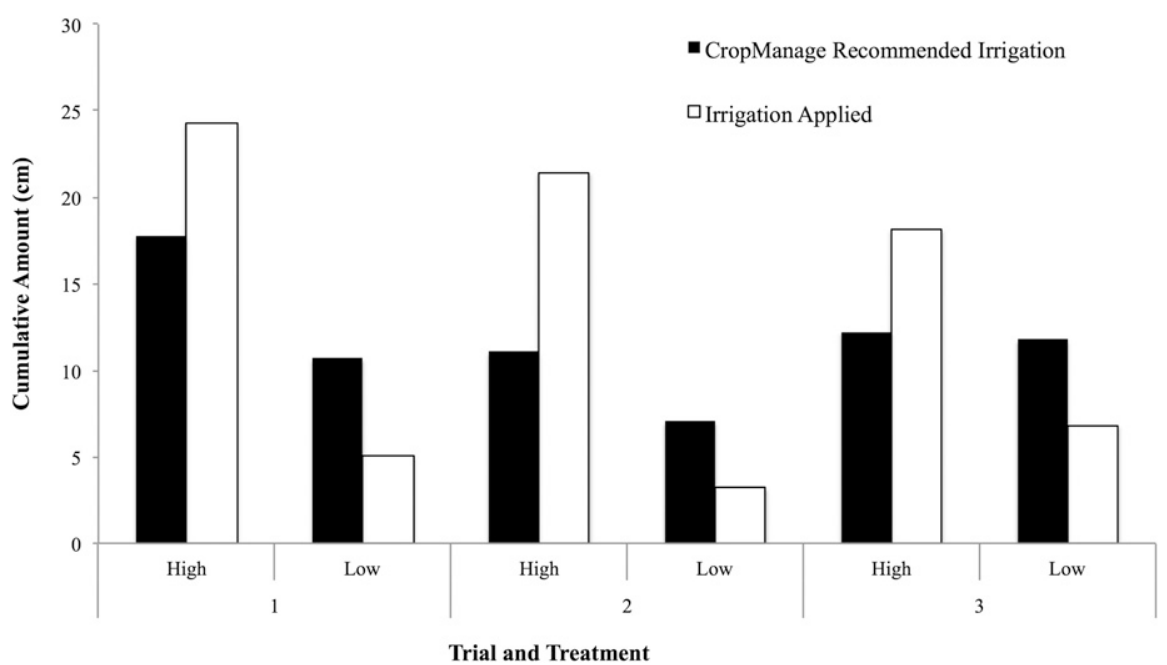

Fig. 1. Recommended drip irrigation by CropManage, compared with applied drip irrigation. Amounts exclude sprinkler irrigation applied before stand establishment. 
point. Core lengths include the height of the bolt for individuals that bolted. Interior leaves were then carefully inspected for tipburn, and the number of leaves with signs of tipburn was recorded. Firmness was scored for crisphead cultivars only, with scores of $1-4$, in which 1 is a loose head and 4 a very firm head (Kader et al., 1973). Scores of 3 are deemed most desirable in the majority of cultivars, indicating a firm, compact, and commercially acceptable head. Lower scores and looser heads are a positive trait only in batavia types.

Data analysis. All analyses were carried out in R v. 3.2.0 and v. 3.2.1 (R Core Team 2015), primarily using packages "stats" (R Core Team 2015), "plyr” (Wickham 2011), and "dplyr" (Wickham and Francois 2015). Analyses of variance (ANOVA) were done among trials and among all cultivars within trials; however, although standard post hoc tests such as Tukey's honestly significant difference (HSD) are appropriately strict to identify significant differences among multiple subjects, our goal was to identify nonsignificant differences among subjects (i.e., we wanted to identify cultivars that grow similarly under high and low water treatments, and thus have a nonsignificant difference in the trait among treatments). Tukey's HSD post hoc multiple comparison tests were done, but are not reported here because they were often too lenient for our purposes. Therefore, all cultivars were analyzed individually to consider differences among high and low water treatments. For numerical measurement data (FW, height, width, and core length), outliers were detected using boxplots, however no outliers were removed from the dataset. We used Shapiro-Wilk tests to evaluate normality and Levene tests to evaluate the homogeneity of variance assumption of parametric analyses. If the data did not meet the assumptions of parametric analyses, the data were transformed using base-10 $\log$ and square root transformations, and Shapiro-Wilk and Levene tests were rerun. For cultivars and traits that met the assumptions of parametric analyses, we conducted two-sample Student's $t$ tests for equal and nonequal variances (Welch $t$ test) among samples in high and low water treatments. For cultivars in which the data were transformed, the means were reported as backtransformed values, and footnotes are used to report the type of transformation. If the data still did not meet the assumptions of parametric analyses after transformation, nonparametric Mann-Whitney $U$ tests were used to consider differences among cultivars and water treatments. The decision to call a difference among samples in high and low water treatments significant was based on an alpha level of 0.05 in Student's $t$ tests, Welch's $t$ tests, or nonparametric Mann-Whitney $U$ tests.

For binomial data (tipburn leaves, bolting, and firmness), various tests were used to evaluate differences in samples among treatments. Tipburn was scored as count data, and differences were evaluated using an $\mathrm{F}$ test for deviance from a generalized linear model with quasi-Poisson errors. Bolting data were recorded as a binary response variable, and the proportions of plants that bolted in high and low water treatments were compared using a binomial exact test. Firmness was scored only for crisphead cultivars, and scores were compared among high and low water treatments using a nonparametric MannWhitney $U$ test.

\section{Results}

\section{Irrigation of trial 1 and trial 2}

Using drip irrigation, flow meters recorded between 23.5 and $83.7 \mathrm{~L} \times 1000$ per $\mathrm{d}$ applied over $16 \mathrm{~d}$ to the high water treatment (trial 1 cumulative amount 942.2 $\mathrm{L} \times 1000$ ), and between 50.3 and $93.9 \mathrm{~L} \times$ 1000 per day applied over $3 \mathrm{~d}$ to the low water treatment (trial 1 cumulative amount $201.0 \mathrm{~L} \times$ 1000). The cumulative recommended irrigation amounts varied by trial based on rainfall and weather patterns. For high water treatments, total cumulative amounts applied after seed establishment (drip irrigation only) approximated $150 \%$ of CropManage recommendations (Fig. 1). The cumulative recommended irrigation for the low water treatments also varied by trial, and applied irrigation after seed establishment during treatments approximated $50 \%$ of the recommended irrigation (Fig. 1).

Tensiometers and Watermark ${ }^{\circledR}$ sensors measure the approximate pressure required for roots to extract water from the soil, thus high values indicate less available soil moisture. Irrigation applied was sufficient to maintain soil water tension between 0 and $48 \mathrm{kPa}$ (or centibars) with an average value of $2.4 \mathrm{kPa}$ in the high water treatment plots, and between 0 and $199 \mathrm{kPa}$, with an average value $59.4 \mathrm{kPa}$ in the low water treatment (Fig. 2A and B). In the high water treatment, the sensors at $20 \mathrm{~cm}$ tended to indicate less soil moisture than the sensors at $46 \mathrm{~cm}$. In the low water treatment, the sensors at $46 \mathrm{~cm}$ tended to indicate less soil moisture than the sensors at $20 \mathrm{~cm}$. The irrigation schedule was sufficient to maintain high soil moisture levels $(<5 \mathrm{kPa})$ in the high water treatment. In the low water treatment, soil moisture ranged widely from highly moist conditions during establishment to dry conditions $(>60 \mathrm{kPa})$ that lasted for six or more days after thinning.

\section{Irrigation of trial 3}

Because of weather patterns, soil moisture was more erratic during trial 3 than trials 1 and 2 , and several days experienced more overlap in soil moisture measurements among high and low treatments (e.g., day 3, 7, 12, 19, and 2028) than in previous trials (Fig. 2C). The water applied was sufficient to maintain soil moisture in the high water treatment at values $<10 \mathrm{kPa}$, corresponding to saturated and moist conditions. On day 7, soil moisture in the high water treatment dropped at $20 \mathrm{~cm}$ as indicated by the Watermark $^{\circledR}$ soil moisture meters that recorded values between 15 and $62 \mathrm{kPa}$. Soil moisture at $20 \mathrm{~cm}$ in the high water treatment dropped again on day 23 to $35 \mathrm{kPa}$, which corresponds to the usual range of irrigation for most soils, according to the Watermark ${ }^{\circledR}$ manufacturer.

\section{Cultivars that produce high biomass under low water conditions}

First, we consider the cultivars that produced high biomass under low water conditions independent of their production under high water conditions. These are cultivars that may have had significant reductions in FW under low water treatment compared with high water treatments, but still produced large heads for their type under adverse conditions. The average of all data for trials 1,2 , and 3 are considered, though some cultivars were not included in trial 3 .

Under low water conditions, butterhead cultivars such as Buttercrunch, North Pole, and Fortune produced heads over $300 \mathrm{~g}$. Neither 'Buttercrunch' nor 'Fortune' bolted during the course of our trials, but most of the samples of the cultivar North Pole bolted during trials 1 and 2 (it was not included in trial 3). Mean core length for 'Buttercrunch' and 'Fortune' was relatively short; however, mean core length for 'North Pole' was longer for all three trials due to its tendency to bolt. The mean number of leaves with signs of tipburn in these plants was also low, with an average of less than one leaf per plant containing tipburn (Table 1).

Cos cultivars such as White Paris SelfFolding, Green Towers, and Paragon PIC all produced heads over $600 \mathrm{~g}$ under the low water treatment (Table 1). There were no leaves with signs of tipburn in 'Green Towers' or 'Paragon PIC' in either trial 1 or 2 , and an average of less than one leaf per plant with tipburn in the cultivar White Paris Self-Folding. The percent of cos plants that bolted during the trials tended to be very high.

Crisphead cultivars such as Cal-West 80 , Heatmaster, and Marion produced heads over $700 \mathrm{~g}$ over the course of two trials. Core lengths were reduced in these cultivars from the high water treatment by an average of $20 \%$ to $30 \%$, and no plants of the cultivars Cal-West 80, Heatmaster, and Marion bolted during the course of the trial, though several other crisphead cultivars did bolt. All crisphead cultivars showed some sign of tipburn among the samples in one or both trials, under both high and low water treatments (Table 1). The high biomass crisphead cultivars had mean firmness scores that indicated firm, commercially acceptable heads.

Leaf type cultivars are typically smaller than most other lettuce types under optimal water conditions, but the reduction in growth of leaf type cultivars grown under low water compared with plants grown under the high water treatment tended to be less than other lettuce types (Table 1). Four green leaf cultivars, including Crispy Sweet, Waldmann's Dark Green, Royal Green, and Ocean Green produced heads over $300 \mathrm{~g}$ with fewer than one leaf per plant with tipburn and no bolting; cores were somewhat extended but still relatively short. 'Red Fire' and 'Cocarde' of the red leaf type produced heads over $300 \mathrm{~g}$ with no signs of tipburn and no bolting. 'Red Fire' had fairly long cores, whereas 'Cocarde' had slightly shorter cores. 

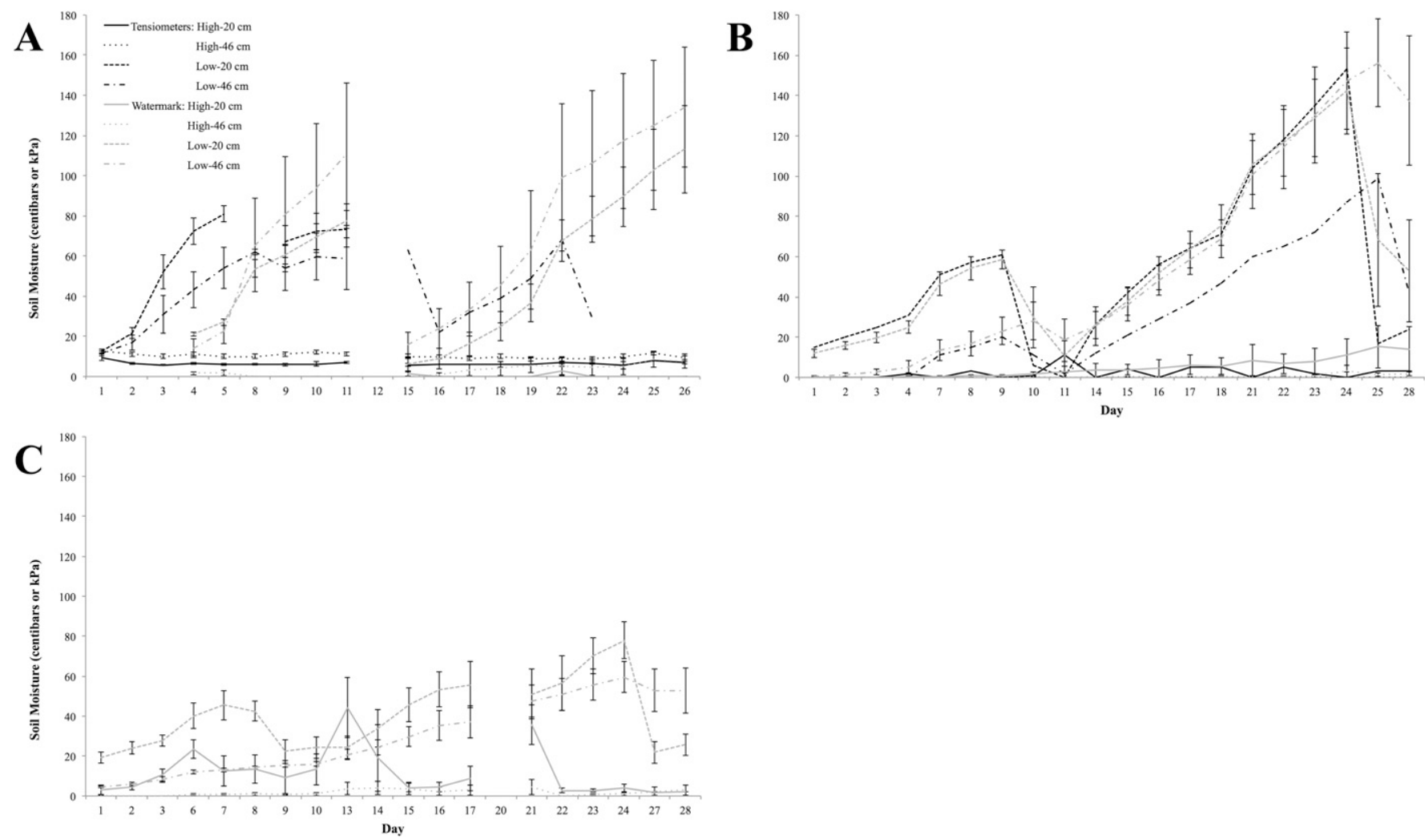

Fig. 2. Soil moisture, measured as the pressure necessary to pull water from the soil in centibars or $\mathrm{kPa}$, from tensiometers and Watermark ${ }^{\circledR}$ sensors in high and low water treatments at depths of 20 and $46 \mathrm{~cm}$ : (A) trial 1, (B) trial 2, and (C) trial 3. Error bars represent the SE on data points derived from readings from multiple instruments. Gaps are missing data. Tensiometers were not used in trial 3.

Stem lettuce varieties such as 'Qing Pi Yuan Ye' and 'Balady W.S.' produced plants over $400 \mathrm{~g}$; and $100 \%$ of the samples of 'Balady W.S.' bolted even under high water, which is desirable in stem lettuce cultivars. Slightly more than half of 'Qing Pi Yuan Ye' samples bolted under low water by harvest time, compared with slightly less than half of the samples under high water.

\section{Cultivar differences among water treatment levels}

As expected, low water conditions generally reduced growth compared with high water conditions. Plants grown under low water treatments tended to have reduced biomass by an average of $39 \% \pm 14$ SD for trial $1,45 \% \pm 22$ SD for trial 2 , and $41 \% \pm$ 16 SD for trial 3 . There was a significant difference in each cultivar's FW among trials ${\text { (factorial ANOVA } \mathrm{F}_{(212,12220)}=2.1, P<}$ $0.001)$, therefore the results of each trial are presented individually.

Trial 1. Thirteen cultivars showed no difference in FW between high and low water treatments (Table 2). The biomass measurements of these cultivars under low water treatment ranged from $73 \%$ (L. serriola 491145 ) to 95\% ('Oakleaf') of the biomass measurements taken under high water treatments.

One butterhead cultivar, Bibb, had no significant difference in FW in trial 1 (difference in means $=72.7 \mathrm{~g}$, Student's $t$ test $_{30}=$ $1.72, P=0.10)$. It also largely maintained the same size under low water treatments as high water treatments; there was no significant reduction in width (difference in means $=$ $1.1 \mathrm{~cm}$, Mann-Whitney $U$ test $=170, P=0.11$ ), and no strongly significant reduction in height (difference in means $=0.7 \mathrm{~cm}$, Mann-Whitney $U$ test $=180, P=0.05$ ). Core length was slightly longer in plants grown under high water treatment than low water (difference in mean $=0.3 \mathrm{~cm}$, Student's $t$ test $_{30}=0.5, P=$ 0.60 ), and none of the plants bolted or showed any evidence of tipburn under either high or low water treatment.

Growth of the crisphead cultivar Kelly generally slowed under low water conditions. There was a relatively minor reduction in mean FW under low water treatment compared with those grown under the high water treatment (difference in means $=143.6 \mathrm{~g}$, Student's $t$ test $_{30}=1.3, P=0.19$ ). Among the traits that measure maturity, 'Kelly' experienced a significant decrease in core length under low water conditions (difference in means $=11.7 \mathrm{~mm}$, Mann-Whitney $U$ test $=$ 201.5, $P=0.005$ ). Growth was not slowed enough by low water conditions to significantly delay bolting; however, notably all of the 'Kelly' plants in the trial bolted under both high and low water treatments. Plants of the cultivar Kelly had significantly more leaves with tipburn under the high water treatment than under low water treatments (Table 2; analysis of deviance, $P=0.006$ ). Treatment did not affect the firmness score (difference in mean score $=0.1$, MannWhitney $U$ test $=136, P=0.35$ ); the cultivar
Kelly generally had no head or very loose head under both treatments.

Six green leaf type cultivars grew similarly under high and low water treatments (Table 2). Among these, individuals of the cultivar Slobolt on average reached $88 \%$ of the mean FW under high water treatments (difference in means $=46.9 \mathrm{~g}$, Student's $t$ test $_{30}=1.1, P=0.26$ ), and individuals of the cultivar Grand Rapids reached $86 \%$ of the average FW under high water treatments (difference in means $=41.3 \mathrm{~g}$, Student's $t$ test $\left._{29}=1.20, P=0.24\right)$. The length of the core was slightly but not significantly longer in 'Slobolt' plants grown under low water conditions than high water conditions (difference in means $=0.1 \mathrm{~cm}$, Mann-Whitney $U$ test $=143.5, P=0.57$ ); however, the core length was slightly shorter in 'Grand Rapids' plants under low water conditions than those grown under high water conditions (difference in means $=0.5 \mathrm{~cm}$, Mann-Whitney $U$ test $=142, P=0.39$ ). Neither of these cultivars under low water treatment showed any sign of tipburn nor did they bolt during the course of the trial.

Under low water treatments, three red leaf cultivars grew to over $83 \%$ of the average FW under high water ('Hyper Red Rumple Waved': difference in means $=40 \mathrm{~g}$, Student's $t$ test $_{30}=1.47, P=0.15$; 'Racy Red': difference in means $=39.8 \mathrm{~g}$, Student's $t$ test $_{29}=1.3, P=0.21$; 'Guardian': difference in means $=58.3 \mathrm{~g}$, Student's $t$ test $_{30}=2.1, P=$ 0.05; Table 2). Each of these cultivars saw 
Table 1. Mean fresh weight, stem core length, percentage of bolted plants, number of leaves that exhibited tipburn, and mean head firmness rating of five cultivars of each of the six commercially important lettuce types that produced the highest mean biomass under low water (50\% evapotranspiration) treatments among three field trials. Mean values of each trait are given with their SD, and are calculated as the mean and SD of all data points from all trials the cultivar was included. Percent growth is calculated as the percent of the average high water fresh weight (FW) that the plant achieved, on average, under low water treatments.

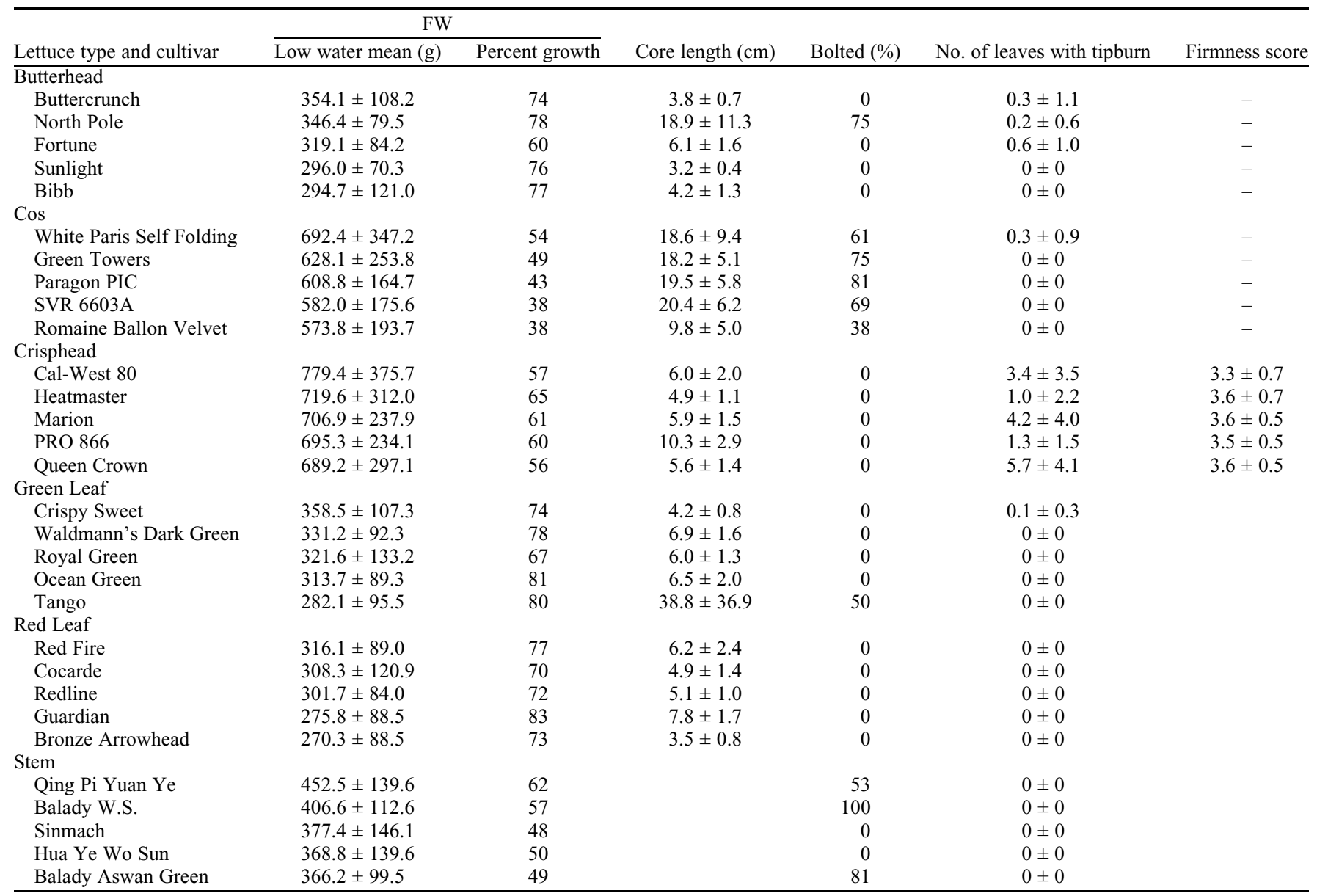

a slight but nonsignificant increase in core length under low water conditions ('Hyper Red Rumple Waved': difference in means $=$ $0.6 \mathrm{~g}$, Mann-Whitney $U$ test $=105.5, P=$ 0.40 ; 'Racy Red': difference in means $=1.3 \mathrm{~g}$, Student's $t$ test $_{29}=-1.9, P=0.07$; 'Guardian': difference in means $=1.3 \mathrm{~g}$, Student's $t$ test $_{30}=$ $-1.9, P=0.07)$. None of these cultivars showed any signs of tipburn regardless of the water treatment level, and none bolted during the course of the trial.

Despite a reputation for drought tolerance (Gallardo et al., 1996; Jackson, 1995), L. serriola lines were not immune to growth reductions under low water treatments. Under low water, these lines only attained a FW between $43 \%$ and $66 \%$ of their average FW under high water treatments, and only one PI line experienced no significant reduction in FW (PI 491145, difference in means $=171.3 \mathrm{~g}$, Student's $t$ test $_{28}=$ 1.5, $P=0.14)$. However, most PI lines continued to grow as tall under low water conditions as their counterparts grown under high water conditions. The L. serriola accession with no significant difference in FW under high and low water treatments (PI 491145) did experience a significant reduction in height under low water (difference of means $=12.0 \mathrm{~cm}$, Mann-Whitney $U$ test $=$ 192, $P=0.001$; Table 2).

Forty-seven cultivars were particularly sensitive to low water conditions and attained an FW under low water conditions that was less than $50 \%$ of their average FW under high water conditions. Nineteen of these cultivars attained less than $40 \%$ of their average high water FW, and one cultivar (Parris Island of the cos type) reached only $29 \%$ of its average high water FW under low water treatments. Among the cultivars with significant reductions in the mean FW from high to low water treatments indicative of low drought tolerance were three cos cultivars: Parris Island (low water FW $29 \%$ of average high water FW, difference in means $=900.5 \mathrm{~g}$, Welch's $t$ test $\left._{19.5}=11.6, P<0.001\right)$, Thermo Cos (low water FW $33 \%$ of average high water $\mathrm{FW}$, difference in means $=891.9 \mathrm{~g}$, Student's $t$ test $\left._{30}=9.8, P<0.001\right)$, and Bionda Lenta a Montare (low water FW 34\% of average high water FW, $746.6 \mathrm{~g}$, Student's $t$ test $\left._{30}=13.1, P<0.001\right)$. Stem lettuce cultivars as a group were also fairly sensitive to low water conditions. All cultivars experienced a significant reduction in FW under low water treatments compared with high water treatments. The cultivar Qing Pi Yan Ye experienced a decrease in FW by a little less than half under the low water treatment (difference in means $=359 \mathrm{~g}$, Student's $t$ test $\left._{29}=6.0, P<0.001\right)$, but a slight increase in height over plants of the same cultivar grown in high water conditions (difference of means $=10.0 \mathrm{~cm}$, Student's $t$ test $_{29}=$ $-3.9, P<0.001)$.

Trial 2. Eleven cultivars exhibited no significant decrease in FW (g) under low water treatments in the second field trial (Table 3). Two cultivars, Waldmann's Green (a green leaf) and Red Tide (a red leaf), produced a higher average biomass under the low water treatment than the high water treatment in this trial, which was not replicated in any other trial (Table 3).

Green leaf cultivars such as Slobolt and Grand Rapids showed no significant difference in both trial 1 ('Slobolt': difference in means $=46.9 \mathrm{~g}$, Student's $t$ test $_{30}=1.14, P=$ 0.26; 'Grand Rapids': difference in means = $41.4 \mathrm{~g}$, Student's $t$ test $_{29}=1.2, P=0.24$ ) and trial 2 ('Slobolt': difference in means $=19.0 \mathrm{~g}$, Student's $t$ test $_{30}=1.5, P=0.15$; Grand Rapids: difference in means $=11.8 \mathrm{~g}$, Student's $t$ test $_{29}=0.5, P=0.59$ ). Under low water treatments in trial 2, 'Slobolt' grew to 


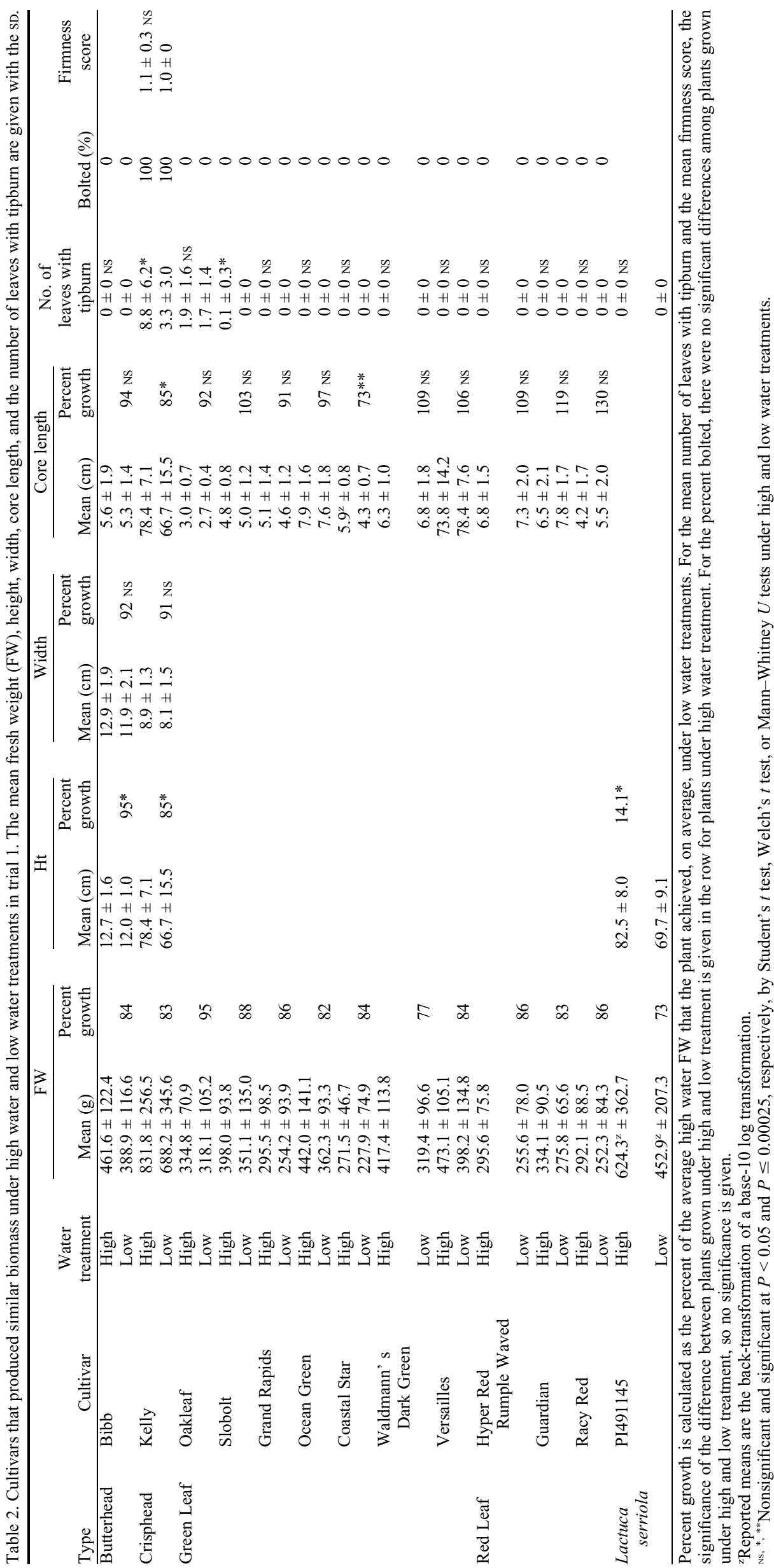


Table 3. Cultivars that produced similar biomass under high water and low water treatments in trial 2 . The mean fresh weight (FW), height, core length, and the number of leaves with tipburn are given with the SD.

\begin{tabular}{|c|c|c|c|c|c|c|c|c|c|c|}
\hline \multirow[b]{2}{*}{ Type } & \multirow[b]{2}{*}{ Cultivar } & \multirow[b]{2}{*}{$\begin{array}{c}\text { Water } \\
\text { treatment }\end{array}$} & \multicolumn{2}{|l|}{ FW } & \multicolumn{2}{|c|}{$\mathrm{Ht}$} & \multicolumn{2}{|c|}{ Core length } & \multirow{2}{*}{$\begin{array}{l}\text { No. of } \\
\text { leaves with } \\
\text { tipburn }\end{array}$} & \multirow[b]{2}{*}{ Bolted (\%) } \\
\hline & & & Mean (g) & $\begin{array}{l}\text { Percent } \\
\text { growth }\end{array}$ & Mean $(\mathrm{cm})$ & $\begin{array}{l}\text { Percent } \\
\text { growth }\end{array}$ & Mean $(\mathrm{cm})$ & $\begin{array}{l}\text { Percent } \\
\text { growth }\end{array}$ & & \\
\hline \multirow[t]{16}{*}{ Green leaf } & Greengo & High & $191.5 \pm 62.2$ & & & & $3 \pm 0.6$ & & 0 & 0 \\
\hline & & Low & $176.6 \pm 61.3$ & 92 & & & $2.9 \pm 0.9$ & $97 \mathrm{NS}$ & 0 & 0 \\
\hline & Slobolt & High & $220.6^{z} \pm 34.1$ & & & & $3.5 \pm 0.5$ & & 0 & 0 \\
\hline & & Low & $201.6^{z} \pm 60.9$ & 91 & & & $3.3 \pm 0.9$ & $94 \mathrm{NS}$ & 0 & 0 \\
\hline & Two Star & High & $228.9 \pm 65.8$ & & & & $3.5 \pm 0.9$ & & 0 & 0 \\
\hline & & Low & $210.8 \pm 34.2$ & 92 & & & $3.5 \pm 0.3$ & $100 \mathrm{NS}$ & 0 & 0 \\
\hline & Grand Rapids & High & $199.7 \pm 76.7$ & & & & $3.8 \pm 1.0$ & & 0 & 0 \\
\hline & & Low & $187.9 \pm 38.4$ & 94 & & & $3.7 \pm 0.8$ & $94 \mathrm{NS}$ & 0 & 0 \\
\hline & Australian & High & $146.9 \pm 44.8$ & & & & $3.1 \pm 0.8$ & & 0 & 0 \\
\hline & & Low & $124.6 \pm 22.8$ & 85 & & & $3.1 \pm 0.4$ & $98 \mathrm{NS}$ & 0 & 0 \\
\hline & Baba & High & $255.9 \pm 51.6$ & & & & $3.2 \pm 0.5$ & & 0 & 0 \\
\hline & & Low & $247 \pm 47.3$ & 97 & & & $3.6 \pm 1.3$ & 114 NS & 0 & 0 \\
\hline & Western Green & High & $265.1 \pm 55.3$ & & & & $4.6 \pm 0.9$ & & 0 & 0 \\
\hline & & Low & $243.2 \pm 54.1$ & 92 & & & $4.8 \pm 0.7$ & 105 NS & 0 & 0 \\
\hline & $\begin{array}{l}\text { Waldmann's } \\
\text { Green }\end{array}$ & High & $81.2 \pm 27.3$ & & & & $3.0 \pm 0.4$ & & & \\
\hline & & Low & $226.7 \pm 75.8$ & 279 & & & $4.5 \pm 1.8$ & $150 \mathrm{NS}$ & & \\
\hline \multirow[t]{4}{*}{ Red leaf } & Red Tide & High & $186.7 \pm 68.6$ & & & & $3.4 \pm 0.6$ & & 0 & 0 \\
\hline & & Low & $188.4 \pm 70.9$ & 101 & & & $3.8 \pm 1.3$ & $110 \mathrm{NS}$ & 0 & 0 \\
\hline & Eruption & High & $179.9 \pm 39$ & & & & $3.8 \pm 0.5$ & & 0 & 0 \\
\hline & & Low & $158 \pm 57.4$ & 88 & & & $3.9 \pm 1.1$ & 102 NS & 0 & 0 \\
\hline \multirow{2}{*}{$\begin{array}{l}\text { Lactuca } \\
\quad \text { serriola }\end{array}$} & PI491149 & High & $169.1^{y} \pm 67$ & & $13.4^{z} \pm 3.6$ & & & & & 0 \\
\hline & & Low & $159.3^{y} \pm 206.2$ & 94 & $8.7^{\mathrm{z}} \pm 8.9$ & $65^{*}$ & & & & 0 \\
\hline
\end{tabular}

Percent growth is calculated as the percent of the average high water FW that the plant achieved, on average, under low water treatments. Width and firmness data are not included because those data were not collected for any of these samples.

${ }^{\mathrm{z}}$ Reported means are the back-transformation of a base-10 $\log$ transformation.

${ }^{\mathrm{y}}$ Reported means are the back-transformation of a square root transformation.

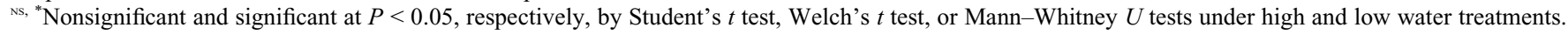

$91 \%$ of the average FW under high water treatment, and 'Grand Rapids' grew to $94 \%$ of its average high water FW. These cultivars also showed no significant differences in core length ('Slobolt': difference in mean $=0.2 \mathrm{~cm}$, Mann-Whitney $U$ test $=$ $171.5, P=0.09$; 'Grand Rapids': 0.05, Student's $t$ test $_{29}=0.2, P=0.88$ ). No plants of either cultivar bolted regardless of treatment, neither was tipburn observed in either water treatment.

Two red leaf cultivars experienced no decrease in FW under high and low treatment. Samples of 'Red Tide' had a slightly higher mean FW under low water treatment than high water treatment (difference in means $=1.7 \mathrm{~g}$, Student's $t$ test $_{25}=-0.1, P=$ $0.95)$, while samples of 'Eruption' had a slightly lower mean FW under low water treatment (difference in means $=21.9 \mathrm{~g}$, Mann-Whitney $U$ test $=177, P=0.07$ ). The length of the core in the red leaf cultivars Red Tide and Eruption was slightly but not significantly longer in plants grown under low water treatment ('Red Tide': difference in means $=0.3 \mathrm{~cm}$, Welch's $t$ test $_{21.9}=-0.9$, $P=0.38$; 'Eruption': difference in means $=$ $0.1 \mathrm{~cm}$, Mann-Whitney $U$ test $=147.5, P=$ $0.45)$, though no plants bolted nor showed any signs of tipburn (Table 3 ). Some of the red leaf cultivars that experienced no significant difference in FW in trial 1 did experience a significant decrease in FW in trial 2 ('Hyper Red Rumple Waved': difference in means $=85.0 \mathrm{~g}$, Student's $t$ test $_{30}=5.8, P<$ 0.001; 'Racy Red': difference in means $=62.6 \mathrm{~g}$, Student's $t$ test $_{30}=3.0, P<0.001$ ).
One L. serriola accession, PI 491149, experienced a slight but nonsignificant decrease in FW under low water treatment compared with high water treatment (difference in means $=$ $9.8 \mathrm{~g}$, Student's $t$ test $_{16}=0.8, P=0.45$ ), but it did experience a significant decrease in height (difference in means $=4.8 \mathrm{~cm}$, Student's $t$ test $_{16}=2.6, P=0.02$ ).

A total of 82 cultivars grew to only $50 \%$ of their average FW under high water when exposed to low water treatments. Sixty-five of those cultivars grew to only $40 \%$ of their average $\mathrm{FW}$ under high water, and 10 grew to less than $30 \%$ of their average $\mathrm{FW}$ under high water. All butterhead cultivars experienced significant reductions in FW under low water treatment in trial 2 . The cultivar Bibb, which grew to $84 \%$ of its average high water biomass under low water treatments in trial 1 , grew to only $70 \%$ of its average high water biomass under low water treatments in trial 2 (difference in means $=$ $108 \mathrm{~g}$, Student's $t$ test $_{26}=5.0, P<0.001$ ). Cos and crisphead cultivars were the most likely to have very high reductions in FW. Cultivars that did relatively well under trial 1 such as the crisphead cultivar Kelly (Table 2) attained only $38 \%$ of their average FW under high water when grown under low water conditions $($ difference in means $=$ $499.3 \mathrm{~g}$, Student's $t$ test $_{22}=7.5, P<0.001$ ) in trial 2. Under low water, the crisphead 'Excell' and the cos 'Romana Bionda Deg' attained only $22 \%$ and $23 \%$, respectively, of their average FW under high water conditions. Stem lettuce cultivars were again very sensitive to low water conditions in trial 2 .
'Balady Aswan Green' attained only about $51 \%$ of its average FW under high water conditions (difference in means $=349.4$, Student's $t$ test $_{30}=8.5, P<0.001$ ) and 'Celtuce' attained only about $52 \%$ of its average FW under high water conditions (difference in means $=277.3 \mathrm{~g}$, Student's $t$ test $\left._{30}=6.4, P<0.001\right)$.

Trial 3. The third trial was a reduced representation of the previous two trials, containing only 50 cultivars of the crisphead, cos, green leaf, red leaf, and butterhead types. Cultivars were selected based on seed availability and performance in previous trials. Seven cultivars had no significant difference in FW in high and low water treatments (Table 4).

Two butterhead cultivars, Interrex and Baccarat, experienced no significant differences in FW in trial 3 ('Interrex': difference in means $=12.9 \mathrm{~g}$, Welch $t$ test $16.3=1.1, P=$ 0.30; 'Baccarat': difference in means $=$ $5.8 \mathrm{~g}$, Student's $t$ test $_{30}=0.8, P=0.43$ ). They maintained a similar size under high and low water treatments; there was no significant difference in height of plants of either cultivar under high or low water treatments ('Interrex': difference in means = $0.1 \mathrm{~cm}$, Student's $t$ test $_{25}=0.2, P=0.85$; 'Baccarat': difference in means $=0.1 \mathrm{~cm}$, Mann-Whitney $U$ test $=132, P=0.89)$, nor a difference in width ('Interrex': difference in means $=0.6 \mathrm{~cm}$, Mann-Whitney $U$ test $=$ 113, $P=0.29$; 'Baccarat': difference in means $=0.2$, Mann-Whitney $U$ test $=$ 124.5, $P=0.90$ ). There was no significant difference in core length ('Interrex': difference 


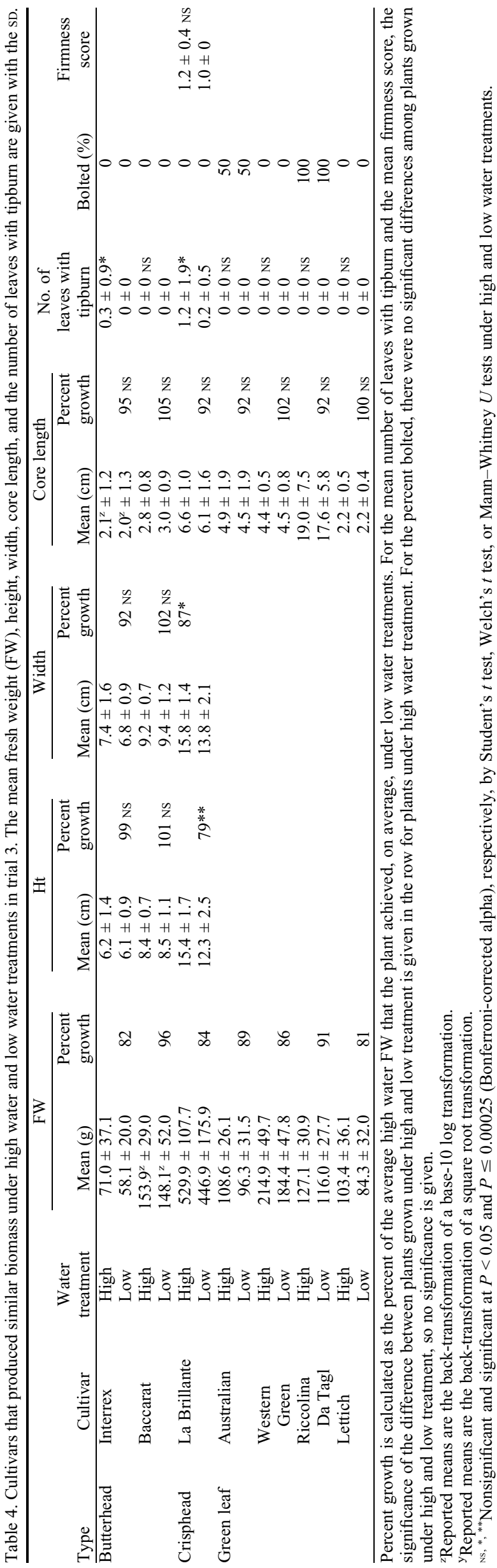

in means $=0.1 \mathrm{~cm}$, Student's $t$ test $_{25}=0.46$, $P=0.65$; 'Baccarat': difference in means = $0.2 \mathrm{~cm}$, Mann-Whitney $U$ test $=119, P=$ $0.74)$, nor did any plants of either cultivar bolt under either high or low water treatment. Plants of the cultivar Interrex had significantly more signs of tipburn under high water treatment (high water: 0.3 leaves \pm 0.9 SD; low water: 0 leaves; analysis of deviance, $P=0.03$ ), though plants of the cultivar Baccarat showed no evidence of tipburn.

The crisphead cultivar La Brillante experienced significant reductions in FW under low water treatments in trials 1 and 2, but no significant differences in $\mathrm{FW}$ in trial 3 (difference in means $=83.0 \mathrm{~g}$, Welch $t$ test $_{30}=1.6, P=0.12$ ). Core length was not significantly different among plants grown in high and low water treatments (difference in means $=0.6 \mathrm{~cm}$, Student's $t$ test $_{30}=1.2$, $P=0.23$ ), and none of the plants bolted during the course of the trial. There were significantly fewer leaves with tipburn in plants grown under low water treatment than in plants grown under high water treatment (analysis of deviance, $P=0.02$; Table 4). Firmness was not significantly different in high and low water treatment (difference in means $=0.2$, Mann-Whitney $U$ test $=152$, $P=0.08)$. The firmness scores of ' $\mathrm{La}$ Brillante' plants grown under high water treatments had a mean value of $1.2 \pm 0.4$, and a mean score under low water treatment was $1.0 \pm 0.0$; these values differ from other scores reported above because 'La Brillante' is a batavia type crisphead in which loose heads are valued, and firm heads are indicative of over maturity.

Green leaf cultivars such as Australian and Western Green that had nonsignificant differences in FW in high and low water treatments in trial 2 also had no significant difference in FW in trial 3 ('Australian': difference in means $=12.4 \mathrm{~g}$, MannWhitney $U$ test $=151.5, P=0.39$; 'Western Green': difference in means $=30.5 \mathrm{~g}$, Student's $t$ test $\left._{30}=1.8, P=0.09\right)$. 'Slobolt' was nonsignificant for differences in $\mathrm{FW}$ in trials 1 and 2, but was not included among the cultivars tested in trial 3. 'Grand Rapids' was also nonsignificant for $\mathrm{FW}$ in trials 1 and 2 and had significant differences in FW in trial 3 (difference in means = $24.9 \mathrm{~g}$, Student's $t$ test $_{30}=2.2, P=0.03$ ). Core length in 'Australian' and 'Western Green' were also not significantly shorter in the low water treatment than the high water treatment in trial 3 ('Australian': difference in means $=0.4 \mathrm{~cm}$, Student's $t$ test $_{30}=0.6$, $P=0.54$; 'Western Green': difference in means $=0.1$, Student's $t$ test $30=-0.4, P=$ 0.71 ), though $50 \%$ of the plants in both high and low water treatments of 'Australian' bolted during trial 3. No plants of the cultivar Western Green bolted, and there was no evidence of tipburn on any 'Australian' or 'Western Green' plant.

Cultivars that were particularly sensitive to low water conditions in trial 3 included the crisphead cultivars Tresor (difference in 
means $=475.5 \mathrm{~g}$, Student's $t$ test $_{30}=8.7, P<$ 0.001 ), and Iceberg (difference in means $=$ 415.9, Student's $t$ test $_{30}=8.8, P<0.001$ ), as well as the butterhead cultivar Novir (difference in means $=125.7$, Welch's $t$ test $_{19.8}=5.1, P<$ 0.001).

\section{Patterns in biomass and maturity traits}

During trial 1, the butterhead cultivar Baccarat under low water conditions attained on average only $81 \%$ of the average FW under high water conditions, but the average core grew to $149 \%$ of the average length under high water. There was a significant increase in the proportion of 'Baccarat' individuals that bolted under low water treatments during the course of the trial (high water: 0.2 ; low water: 0.9 ; exact binomial test $=14.5, P<0.001$ ). During trial 2, even though this cultivar attained only $77 \%$ of its average high water FW, there was no concomitant significant reduction in core length under low water treatments (high water mean $=3.2 \mathrm{~cm} \pm 0.5 \mathrm{SD}$; low water mean $=3.0 \mathrm{~cm} \pm 0.4 \mathrm{sD}$; Mann-Whitney $U$ test $=145, P=0.45)$. Trial 3 was an anomaly, in that there was no significant decrease in FW among 'Baccarat' samples (Student's $t$ test ${ }_{30}=0.8, P=0.43$; Table 4), and no significant difference in core length (Mann-Whitney $U$ test $=119, P=0.74$; Table 4).

The general pattern of reductions in biomass with no concomitant reduction in core length, or an increase in core length, is also found in a number of cultivars of every type, though the differences are not as significant as for the cultivar Baccarat. Many cultivars that experienced a significant reduction in FW from high to low water treatments, experienced no concomitant significant reduction in core length. For example, 'Thermo Cos' attained only $33 \%$ of its average high water FW under low water conditions (difference in means $=891.9 \mathrm{~g}$, Student's $t$ test $_{30}=$ $9.8, P<0.001$ ), but we measured no significant difference in core length (different in means = $1.8 \mathrm{~cm}$, Mann-Whitney $U$ test $=139, P=$ 0.69). Among all data, there is a weak correlation between FW and core length under high water treatments (Pearson's $r=0.14-0.42$ for trials $1-3, P<0.001$; Fig. $3 \mathrm{~A}, \mathrm{C}$, and $\mathrm{E}$ ), and that correlation becomes weaker under the low water treatment (Pearson's $r=0.09-0.32, P<$ 0.005; Fig. 3B, D, and F).

\section{Discussion}

Under low water treatments, most cultivars in each of three trials saw significant declines in FW, height, width, and core length, as well as reduced incidence of tipburn. Low water treatments reduced biomass by an average of $39 \%$ for trial 1 , and $43 \%$ for trial 2 . Drought stress, as one might expect, appears to cause lettuce plants to reduce growth. Some cultivars, however, appear to produce more biomass under low water conditions than others, which highlights differences among cultivars that can be used by breeders to develop drought tolerant lines.
Growth reduction and cessation is a wellestablished response of plants to chronic drought stress, and important for long-term survival of the plant to moderate drought stress or short-term severe drought events. As soil water supplies diminish, water uptake decreases even as water loss via ET continues, resulting in a deficit. As this deficit becomes more severe, the RWC and the water potential of the cells are reduced, and stomata in the leaf close, which slows transpiration and conserves water. Photosynthesis is also reduced, either as a result of decreasing $\mathrm{CO}_{2}$ when the stomata close (Cornic and Briantais, 1991; Dietz and Heber, 1983) or due to reductions in the Calvin cycle (Tezara et al., 1999), and growth is thus impaired until cellular water potential improves. Most plant physiologists refer to this strategy for surviving drought stress as drought avoidance or dehydration postponement (Chaves et al., 2003; Turner, 1979, 1997). Drought avoidance can also be achieved by allocating limited resources to different organs, such as roots rather than leaves, so water uptake can be maximized; research has previously shown that lettuce copes with drought by adjusting growth patterns in the roots (Jackson, 1995; Kerbiriou et al., 2013).

In addition to drought avoidance, another nonmutually exclusive strategy to cope with drought stress is referred to as drought escape (Turner, 1979, 1997), which involves developmental plasticity and the ability of the plant to re-allocate resources to speed up its life cycle to flower and set seed before water deficits in the plant become fatal. Flowering in lettuce is precipitated by bolting, caused by the elongation of the flowering stalk from the core at maturity. The emergence of the flowering stalk in cultivars aside from stem lettuce results in increased bitterness and poor head shape, both of which are less desirable traits in nonstem cultivars and have been selected against during the course of the domestication of lettuce (Mou, 2007). We measured core length as an indicator of maturity, with longer cores indicating a later stage toward bolting. As the core is a component of the plant, it contributes toward FW, and if FW is reduced, the size of the core should be likewise reduced. Generally, this was true. Biomass and core length were correlated, albeit somewhat weakly under high water treatments (Fig. 3). The weakness of the correlation may be explained by the diversity of cultivars used in this study, and perhaps by varied results of agricultural selection against core growth (i.e., selection against core growth may be more successful in some cultivars than in others). In general, the correlation between FW and core length became even weaker under low water treatment (Fig. 3). There were a number of cultivars (e.g., thermos Cos) that had significantly reduced biomass under low water treatment compared with high water treatment, but no significant difference in core length among treatments. One cultivar (Baccarrat) had a significantly longer core under low water treatment than under high water treatment. This suggests that lettuce, when stressed, can redirect resources from general biomass production to achieve maturity as a drought escape strategy.

This project provides evidence that lettuce can use both avoidance and escape strategies in responding to drought stress. Both strategies are detrimental to commercial lettuce production: biomass accumulation is generally the goal of the lettuce industry and decreased growth reduces commercial value. Premature bolting and flowering results in bitter flavors and thus product with reduced commercial value. Most cultivars experienced a reduction in $\mathrm{FW}$ in low water treatments as they reduced growth to conserve water (drought avoidance), and some apparently reallocated resources to growth of traits that are required for seed production, such as to the core in preparation for bolting (drought escape). However, there is variation among cultivars to the degree by which they use one strategy or the other, and variation in the degree by which their commercially valuable traits are affected by drought. The variation among cultivars can be used by breeders to develop new cultivars with increased drought tolerance, while still maintaining important commercial traits.

The process of developing cultivars with minimal reductions in growth and no hastening of maturity under low water conditions takes time. Growers who want to reduce their water use immediately may experience less reduction in profit by planting varieties that we found to have high biomass under low water treatments, or cultivars with reproducible nonsignificant reductions in biomass (FW).

Crisphead cultivars such as Cal-West 80 , Heatmaster, and Marion produced heads of $700 \mathrm{~g}$ and higher under low water treatments in trials 1 and 2 with minimal negative traits such as bolting, but tipburn was present on a number of samples (though it was more prevalent under samples grown under high water treatments). The cultivar Kelly produced heads with no significant reduction in FW in trial 1 , but those results were not reproducible, and we misjudged the time to harvest maturity and allowed all plants to bolt by the time of sampling. Cos cultivars tended to bolt under low water conditions, though they produced fairly large heads with very little evidence of tipburn. Further optimization may be necessary to grow cos cultivars under low water conditions to more accurately judge the time to harvest maturity. Butterhead cultivars such as Buttercrunch and Fortune produced fairly large heads with no bolting and very little tipburn, and may be good options for growers looking to grow high biomass cultivars under low water conditions. Green and red leaf cultivars tended to have the lowest reductions in FW under low water treatments compared with high water treatments; bolting was generally rare (exception was the green leaf 'Australian') with no evidence of tipburn (Table 1). Cultivars with reproducible nonsignificant differences in growth were leaf types, which are typically 


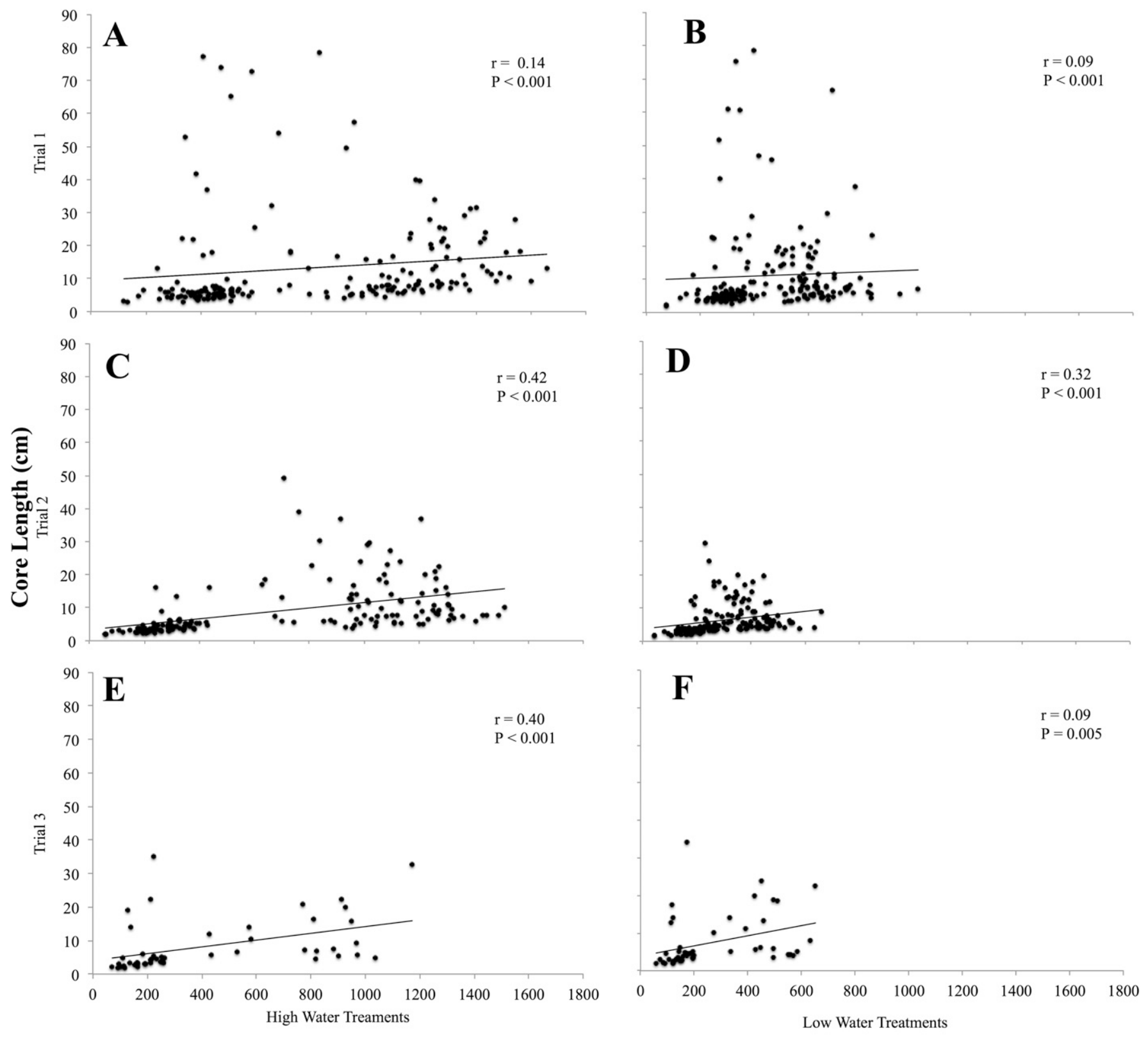

FW (g)

Fig. 3. Correlation of fresh weight $(\mathrm{FW})$ in grams by core length $(\mathrm{cm})$ for high and low water treatments for each trial. (A) Trial 1, high water treatment. (B) Trial 1 , low water treatment. (C) Trial 2, high water treatment. (D) Trial 2, low water treatment. (E) Trial 3, high water treatment. (F) Trial 3, low water treatment.

fast growing and harvested early before soil moisture was significantly reduced. These cultivars typically experienced a reduction in $\mathrm{FW}$, indicating a general reduction in growth, though the difference was not statistically significant. The green leaf types 'Slobolt' and 'Grand Rapids' had no significant difference in growth among high and low water treatments in trials 1 and 2 , and the green leaf types 'Australian' and 'Western Green' had no significant difference in growth among high and low water treatments in trials 2 and 3 . The shorter time from planting to harvest for green and red leaf types may reduce the impacts of ongoing drought stress in the leaf type lettuces, and reduce overall water consumption for growers. Stem lettuce cultivars that produced high biomass included Qing Pi Yuan Ye and Balady W.S. Stem lettuce, however, was generally very sensitive to low water conditions; all stem lettuce cultivars experienced significant reductions in FW across all trials.

As the major lettuce-growing regions of the United States continue to face significant drought, lettuce production has the potential to decline with growers suffering increasing losses. Lettuce production is highly dependent on irrigation, and efforts to identify QTLs for marker-assisted selection toward drought-resistant varieties have thus far been somewhat inconclusive (Hartman et al., 2014; Johnson et al., 2000; Uwimana et al., 2012; Wei et al., 2014). Understanding how different cultivars perform under low water conditions allows us to understand the diversity of physiological responses of this plant to drought and to take a different approach to developing tolerant cultivars. Growers may benefit to see how their choice of cultivar affects crop performance under low water conditions, and they may note other cultivar options that may buffer crop reductions in periods of chronic drought stress. The increased use of certain droughttolerant cultivars and the improvement of future breeding lines could allow lettuce production to return to the Central Valley of California, where lettuce production has largely ceased due to the decreased availability of water. The cultivars that performed well in our trials could be used in a breeding program to further improve the 
tolerance to drought stress in lettuce and will serve as the basis for molecular analyses to identify a more complete profile of drought stress responses in all lettuce types.

\section{Literature Cited}

Atkinson, L.D., L.K. McHale, M.J. Truco, H.W. Hilton, J. Lynn, J.W. Schut, R.W. Michelmore, P. Hand, and D.A. Pink. 2013. An intra-specific linkage map of lettuce (Lactuca sativa) and genetic analysis of postharvest discolouration traits. Theor. Appl. Genet. 126(11):2737-2752.

Cahn, M.D. 2009. UC IPM Pest Management Guidelines: Lettuce. UC ANR Publication 3450. General Information. 13 July 2015 . <http://ipm.ucdavis. edu/PMG/r441311511.html\#LETTUCE $>$.

Cahn, M., R. Smith, T. Hartz, and B. Noel. 2013 Irrigation and nitrogen management web-based software for lettuce production. Western Nutrient Management Conf. Mar. 7-8, 2013, Reno, NV. p. 11-16.

Chaves, M.M., J.P. Maroco, and J.S. Pereira. 2003. Understanding plant responses to droughtFrom genes to the whole plant. Funct. Plant Biol. 30:239-264.

Cornic, G. and J.-M. Briantais. 1991. Partitioning of photosynthetic electron flow between $\mathrm{CO}_{2}$ and $\mathrm{O}_{2}$ reduction in a $\mathrm{C}_{3}$ leaf (Phaseolus vulgaris L.) at different $\mathrm{CO}_{2}$ concentrations and during drought stress. Planta 183:178-184.

Dietz, K.-J. and U. Heber. 1983. Carbon dioxide gas exchange and the energy status of leaves of Primula palinuri under water stress. Planta 158:349-356.

Gallardo, M., L.E. Jackson, and R.B. Thompson. 1996. Shoot and root physiological responses to localized zones of soil moisture in cultivated and wild lettuce (Lactuca spp.). Plant Cell Environ. 19(10):1169-1178.

Hartman, Y., D.A.P. Hooftman, B. Uwimana, M.E. Schranz, C.C.M. van de Wiel, M.J.M. Smulders, R.G.F. Visser, R.W. Michelmore, and P.H. van
Tienderen. 2014. Abiotic stress QTL in lettuce crop-wild hybrids: Comparing greenhouse and field experiments. Ecol. Evol. 4(12):2395-2409.

Jackson, L.E. 1995. Root architecture in cultivated and wild lettuce (Lactuca spp.). Plant Cell Environ. 18(8):885-894.

Johnson, W.C., L.E. Jackson, O. Ochoa, R. van Wijk, J. Peleman, D.A. St Clair, and R.W Michelmore. 2000. Lettuce, a shallow-rooted crop, and Lactuca serriola, its wild progenitor, differ at QTL determining root architecture and deep soil water exploitation. Theor. Appl. Genet. 101(7):1066-1073.

Kader, A.A., W.J. Lipton, and L.L. Morris. 1973. Systems for scoring quality of harvested lettuce. HortScience 8:408-409.

Kerbiriou, P.J., T.J. Stomph, P.E.L. Van Der Putten, E.T. Lammerts Van Bueren, and P.C. Struik. 2013. Shoot growth, root growth and resource capture under limiting water and $\mathrm{N}$ supply for two cultivars of lettuce (Lactuca sativa L.). Plant Soil 371(1-2):281-297.

Kesseli, R., O. Ochoa, and R. Michelmore. 1991. Variation at RFLP loci in Lactuca spp. and origin of cultivated lettuce (L. sativa). Genome 34(3):430-436.

Knepper, C. and B. Mou. 2015. Semi-high throughput screening for potential drought-tolerance in lettuce (Lactuca sativa) germplasm collections. J. Vis. Expt. 98. doi: 10.3791/52492.

Mou, B. 2007. Lettuce, p. 73-114. In: J. Prohens-Tomás and F. Nuez (eds.). Vegetables I: Asteraceae, Brassicaceae, Chenopodicaceae, and Cucurbitaceae. Springer Science \& Business Media, New York, NY.

R Core Team. 2015. R: A language and environment for statistical computing. R Foundation for Statistical Computing, Vienna, Austria. 16 Apr. 2015. <http://www.R-project.org/>.

Tezara, W., V.J. Mitchell, S.D. Driscoll, and D.W. Lawlor. 1999. Water stress inhibits plant photosynthesis by decreasing coupling factor and ATP. Nature 401:914-917.
Truco, M.J., R. Antonise, D. Lavelle, O. Ochoa, A. Kozik, H. Witsenboer, S.B. Fort, M.J.W. Jeuken, R.V. Kesseli, P. Lindhout, R.W. Michelmore, and J. Peleman. 2007. A high-density, integrated genetic linkage map of lettuce (Lactuca spp.). Theor. Appl. Genet. 115(6):735-746.

Truco, M.J., H. Ashrafi, A. Kozik, H. van Leeuwen, J. Bowers, S. Reyes Chin Wo, K. Stoffel, H. Xu, T. Hill, A. Van Deynze, and R.W. Michelmore. 2013. An ultra-high-density, transcript-based, genetic map of lettuce. G3 (Bethesda) 3(4): 617-631.

Turner, N.C. 1979. Drought resistance and adaptation to water deficits in crop plants, p. 343372. In: H. Mussell and R.C. Staples (eds.). Stress physiology in crop plants. Wiley, New York, NY.

Turner, N.C. 1997. Further progress in crop water relations. Adv. Agron. 58(1):293-338.

U.S. Department of Agriculture, National Agricultural Statistics Service (USDA NASS). 2015. Vegetables. 2014 Summary.

Uwimana, B., M.J.M. Smulders, D.A.P. Hooftman, Y. Hartman, P.H. van Tienderen, J. Jansen, L.K. McHale, R.W. Michelmore, C.C.M. van de Wiel, and R.G.F. Visser. 2012. Hybridization between crops and wild relatives: The contribution of cultivated lettuce to the vigour of crop-Wild hybrids under drought, salinity and nutrient deficiency conditions. Theor. Appl. Genet. 125(6):1097-1111.

Wei, Z., M.M. Julkowska, J.-O. Laloë, Y. Hartman, G.-J. de Boer, R.W. Michelmore, P.H. van Tienderen, C. Testerink, and M.E. Schranz. 2014. A mixed-model QTL analysis for salt tolerance in seedlings of crop-wild hybrids of lettuce. Mol. Breed. 34(3):1389-1400.

Wickham, H. 2011. The split-apply-combine strategy for data analysis. J. Stat. Softw. 40(1):1-29.

Wickham, H. and R. Francois. 2015. dplyr: A grammar of data manipulation. $\mathrm{R}$ package version 0.4.3. 1 Sept. 2015. <http://CRAN.Rproject.org $/$ package $=$ dplyr $>$. 